\title{
A novel paclitaxel-loaded poly(D,L-lactide-co- glycolide)-Tween 80 copolymer nanoparticle overcoming multidrug resistance for lung cancer treatment
}

\author{
This article was published in the following Dove Press journal: \\ International Journal of Nanomedicine \\ 25 May 2016 \\ Number of times this article has been viewed
}

\author{
Xun Yuan ${ }^{1, *}$ \\ Wenxiang $\mathrm{Ji}^{2, *}$ \\ Si Chen' \\ Yuling $\mathrm{Bao}^{3}$ \\ Songwei $\operatorname{Tan}^{3}$ \\ Shun $\mathrm{Lu}^{2}$ \\ Kongming $\mathrm{Wu}^{\prime}$ \\ Qian Chu' \\ 'Department of Oncology, Tongji \\ Hospital of Tongji Medical College, \\ Huazhong University of Science and \\ Technology, Wuhan, ${ }^{2}$ Lung Tumor \\ Clinical Medical Center, Shanghai \\ Chest Hospital, Shanghai Jiao Tong \\ University, Shanghai, ${ }^{3}$ School of \\ Pharmacy, Tongji Medical College, \\ Huazhong University of Science and \\ Technology, Wuhan, People's Republic \\ of China \\ *These authors contributed equally to \\ this work
}

\begin{abstract}
Drug resistance has become a main obstacle for the effective treatment of lung cancer. To address this problem, a novel biocompatible nanoscale package, poly(D,L-lactideco-glycolide)-Tween 80, was designed and synthesized to overcome paclitaxel (PTX) resistance in a PTX-resistant human lung cancer cell line. The poly(D,L-lactide-co-glycolide) (PLGA)Tween 80 nanoparticles (NPs) could efficiently load PTX and release the drug gradually. There was an increased level of uptake of PLGA-Tween 80 in PTX-resistant lung cancer cell line A549/T, which achieved a significantly higher level of cytotoxicity than both PLGA NP formulation and Taxol ${ }^{\circledR}$. The in vivo antitumor efficacy also showed that PLGA-Tween $80 \mathrm{NP}$ was more effective than Taxol $^{\circledR}$, indicating that PLGA-Tween 80 copolymer was a promising carrier for PTX in resistant lung cancer.
\end{abstract}

Keywords: poly(D,L-lactide-co-glycolide), Tween 80, nanoparticle, drug resistance, lung cancer

\section{Introduction}

Due to lack of early detection or screening test, lung cancer patients are often not recognized and diagnosed until they have reached advanced stages, resulting in a poor 5 -year overall survival rate of $16.8 \%$ in the USA, whereas the outcomes are worse in the developing world. ${ }^{1}$ Presently, Taxol ${ }^{\circledR}$ is among the first-line formulations of paclitaxel (PTX) that is usually involved in the treatment of non-small-cell lung cancer, which has the highest mortality rate among cancers. ${ }^{2}$ However, Cremophor EL, an adjuvant used in the formulation of Taxol ${ }^{\circledR}$, has been associated with severe side effects, including allergic reactions, nephrotoxicity, and neurotoxicity. ${ }^{3}$ Besides, PTX resistance is seen in over $70 \%$ of initially diagnosed patients and almost all recurrent patients. Anticancer drug resistance poses one of the biggest challenging threats to successful lung cancer chemotherapy. It is reported that tumor cells develop chemoresistance through mechanisms such as overexpression of ATP-driven multidrug resistance (MDR) efflux transporters (P-glycoprotein [p-gp]), apoptosis-associated protein Bcl-2, and nuclear factor kappa B. ${ }^{4}$ Among these, the membrane-bound p-gp-mediated resistance to PTX is frequently observed in cancer. ${ }^{5}$ p-gp, a product of the $A B C B 1$ (MDR1) gene, is a pump that effluxes out the drug from cells, thus reducing intracellular drug accumulation. ${ }^{6}$ Some p-gp inhibitors have shown restoration of cancer cell sensitivity to chemotherapy drugs. ${ }^{7}$ However, a major problem with p-gp inhibitors is that they
Department of Oncology, Tongji Hospital of Tongji Medical College, Huazhong University of Science and Technology, 1095 Jiefang Avenue, Wuhan 430030,

People's Republic of China

Tel +862783663631

Fax +862783663630

Email qianchu@tjh.tjmu.edu.cn (c) (1) () 2016 Yuan et al. This work is published and licensed by Dove Medical Press Limited. The full terms of this license are available at https://www.dovepress.com/terms.php cc. hereby accept the Terms. Non-commercial uses of the work are permitted without any further permission from Dove Medical Press Limited, provided the work is properly attributed. For permission for commercial use of this work, please see paragraphs 4.2 and 5 of our Terms (https://www.dovepress.com/terms.php). 
may also block anticancer drug efflux from normal cells, thus increasing the toxic effects of chemotherapy. ${ }^{8}$

In order to eliminate the Cremophor EL and in an attempt to reduce the exposure of normal cells to PTX and p-gp inhibitors, alternative formulations have been extensively researched, such as emulsion, micelle, liposome, and nanoparticles (NPs) ${ }^{9-11}$ Nanomedicine, using NPs to simultaneously deliver p-gp inhibitor along with the anticancer drug, holds the greatest promise for these purposes in cancer treatment. ${ }^{12}$ It is well known that NPs passively extravasate tumors through capillaries surrounding the tumor tissue via the enhanced permeation and retention effect, leading to the targeted delivery of anticancer drug into the tumor tissue and reducing side effects. ${ }^{13}$ Besides, NPs could overcome cancer drug resistance by a mechanism of encapsulating drug and reducing their efflux from cells. ${ }^{14}$ In addition, NPs could be controlled to release the drug gradually and effectively, and prolong the circulation half-life of drug in plasma, which demonstrates that the application of NPs in anticancer drug delivery systems shows superiority over the conventional chemotherapy. ${ }^{15} \mathrm{NPs}$, made of natural or synthetic macromolecules, have been extensively explored by scientists. ${ }^{16-19}$ The unique physical properties allow them to be used as imaging probes to locate and identify cancerous lesions. Apart from the application in cancer diagnosis, there has been a great interest in developing new nanomaterials for cancer treatment. ${ }^{20,21}$ Poly (D,L-lactide-co-glycolide) (PLGA), a biodegradable and biocompatible synthetic polymer approved by the US Food and Drug Administration, is widely used in drug delivery system. ${ }^{22-24}$ Various studies have reported that multiple drug resistance could be overcome by PLGA NPs codelivering anticancer drug and p-gp inhibitors, indicating that PLGA NPs may be a promising approach to overcome drug resistance. ${ }^{25}$ Recently, a surge of interest using pluronic block copolymers, which consist of p-gp inhibitors to reverse drug resistance, has emerged due to their unique properties in the inhibition of drug efflux pump. ${ }^{26}$ Tween 80 , a complex mixture of polyoxyethylene ethers used as emulsifiers or dispersing agents in pharmaceuticals, has also been demonstrated to function as a p-gp inhibitor. ${ }^{27,28}$

In the present work, we successfully synthesized PLGATween 80 copolymer, which combined the advantages of PLGA and Tween 80 to convey chemotherapeutic agent PTX and reverse drug resistance. We investigated the physicochemical properties of PTX-loaded polymeric NPs, including size, zeta potential, and PTX release profile. The in vitro cytotoxicity, cellular uptake, cell cycle assay, and cellular apoptosis of PLGA-Tween 80 NPs in A549 and A549/T cells and in vivo antitumor efficacy in the model of lung cancer exnografts in nude mice were also evaluated. PLGA-Tween 80 NPs were first attempted and prospected to reverse resistance to PTX in lung cancer.

\section{Materials and methods Materials}

PTX was purchased from Huafeng United Technology Co., Ltd. (Beijing, People's Republic of China). PLGA$\mathrm{COOH}$ was purchased from Shandong Institute of Medical Instruments (Jinan, People's Republic of China). D-alpha tocopheryl polyethyleneglycol 1000 succinate (TPGS), $\mathrm{N}, \mathrm{N}^{\prime}$-dicyclohexylcarbodiimide (DCC), Tween $80, \mathrm{~N}$ hydroxysuccinimide (NHS), propidium iodide (PI), RNase A, Coumarin-6 (C-6), and trypsin-EDTA were obtained from Sigma-Aldrich Co. (St Louis, MO, USA). RPMI 1640 medium, penicillin-streptomycin, fetal bovine serum, and phosphate-buffered saline (PBS) were purchased from Hyclone (Logan, UT, USA). 3-(4,5-Dimethylthiazol-2-yl)-2,5-diphenyl tetrazolium bromide (MTT) and 4',6-Diamidino-2-Phenylindole,Dihydrochloride were purchased from Biosharp (Hefei, People's Republic of China). Annexin V-FITC/PI double staining assay kit was supplied by KeyGen Biotech Co. Ltd (Nanjing, People's Republic of China). Trypan blue was purchased from TianGen (Beijing, People's Republic of China). Taxol ${ }^{\circledR}$ (PTX for injection) was procured from Bristol-Myers Squibb Trading Co., Ltd. (Shanghai, People's Republic of China). All other reagents were of analytical grade.

\section{Cell culture}

The human lung adenocarcinoma cell line (A549) and PTXresistant human lung cancer cells (A549/T) were purchased from the KeyGen Biotech Co. Ltd. A549 cells were cultured in RPMI 1640 medium supplemented with $10 \%$ fetal bovine serum, $100 \mathrm{U} \mathrm{mL}^{-1}$ penicillin G sodium, and $100 \mu \mathrm{g} \mathrm{mL}^{-1}$ streptomycin sulfate (complete 1640 medium). A549/T cells were cultured in complete 1640 medium with additional $100 \mathrm{ng} \mathrm{mL}-1$ PTX. Cells were maintained at $37^{\circ} \mathrm{C}$ in a humidified and $5 \% \mathrm{CO}_{2}$ incubator. Ethical approval was not deemed necessary for this study according to the Ethical Committee of Tongji Hospital, Tongji Medical College, Huazhong University of Science and Technology.

\section{Animals}

Male Balb/c nude mice, 5 weeks old and weighing 18-20 g, were purchased from Beijing HFK Bio-Technology Co., Ltd. (Beijing, People's Republic of China; certificate no SCXK 14-01-10-29G). The animals were housed at $25^{\circ} \mathrm{C} \pm 1{ }^{\circ} \mathrm{C}$ and $60 \% \pm 10 \%$ humidity under a 12 -hour light-dark cycle during 
the experiments. All animal experiments were performed in accordance with the principles of care and use of laboratory animals under the approval of the Ethics Committee of Huazhong University of Science and Technology.

\section{Synthesis and characteristics of PLGA- Tween 80}

PLGA-Tween 80 conjugate was synthesized by an esterification reaction (Figure 1). Briefly, $3.9 \mathrm{~g}$ of predried PLGA$\mathrm{COOH}(0.3 \mathrm{mmol}), 0.075 \mathrm{~g}$ of DCC $(0.36 \mathrm{mmol})$, and $0.041 \mathrm{~g}$ of NHS $(0.36 \mathrm{mmol})$ were dissolved in $20 \mathrm{~mL}$ of anhydrous DCM with magnetic stirring for 24 hours at room temperature. Then, $0.78 \mathrm{~g}$ of Tween $80(0.6 \mathrm{mmol})$ was added in the liquid medium and reacted for 48 hours. The reacted solution was filtered with filter paper and precipitated in methanol two times to remove unreacted DCC and NHS. The structure of polymer was confirmed by ${ }^{1} \mathrm{H}-\mathrm{NMR}$ spectra (Bruker AM-400 spectrometer; Bruker, Lausanne, Switzerland) and Fourier transform infrared (FTIR) spectroscopy (Bruker VERTEX 70 spectrophotometer; Bruker, Karlsruhe, Germany).

\section{Preparation of PTX-loaded NPs}

PTX-loaded NPs of PLGA and PLGA-Tween 80 were fabricated by a classical nanoprecipitation technique. Briefly, PLGA or PLGA-Tween 80 (19 mg) and PTX (1 mg) were dissolved in $2 \mathrm{~mL}$ of acetone by mild sonication. TPGS was dissolved into aqueous phase to reach $2 \mathrm{mg} \mathrm{mL}^{-1}$ concentration. The organic phase was subsequently added dropwise into the aqueous phase under magnetic stirring and then evaporated after 3 hours under vigorous stirring. The NP suspension was first centrifuged at $1,500 \mathrm{rpm}$ for 10 minutes to remove large particles and aggregations and then filtered with a molecular weight cutoff of $20 \mathrm{kDa}$ to collect the NPs. The resultant NP suspension was then recovered by centrifugation twice at $11,500 \mathrm{rpm}$ for 20 minutes at $4^{\circ} \mathrm{C}$. The resultant products were washed twice to remove unloaded PTX and then resuspended in water before lyophilization to get NP powder. The fluorescent NPs were prepared in the same way with PTX replaced by C-6. The sterilized NPs were made with similar method in the superclean bench under sterile conditions. Blank NPs consisting of only PLGA or PLGA-Tween 80 (without PTX loaded) were prepared for the toxicity evaluation.

\section{Characteristics of PTX-loaded NPs}

The surface morphology of PLGA and PLGA-Tween 80 was evaluated by transmission electron microscope (Tecnai G2 20, FEI, Eindhoven, the Netherlands). The particle size and surface charge of PTX-loaded PLGA and PLGA-Tween 80 were determined by dynamic light scattering (Zeta Plus; Brookhaven Instruments Corporation, Holtsville, NY, USA). The drug-loading content of the NPs was determined by highperformance liquid chromatography (Hitachi L-2000; Hitachi Ltd., Tokyo, Japan) using a reverse phase Inertsil ${ }^{\circledR}$ ODS-3 C18 column $(150 \mathrm{~cm} \times 4.6 \mathrm{~mm}$, pore size $5 \mu \mathrm{m}$; Agilent Technologies, Santa Clara, CA, USA) with a mobile phase consisting of acetonitrile and purified water (50/50, v/v) at a flow rate of $1.0 \mathrm{~mL} \mathrm{~min}{ }^{-1}$. The effluents were monitored three times to detect PTX at $227 \mathrm{~nm}$ with a UV/vis detector and quantified by comparing the peak areas with the standard curve.

Drug release experiments were carried out in vitro as follows. In brief, $10 \mathrm{mg}$ samples of PLGA and PLGA-Tween 80 NPs were separately introduced into a dialysis bag (molecular weight cut-off $=5,000 \mathrm{Da}$ ), and the end-sealed dialysis bag was submerged fully into $25 \mathrm{~mL}$ of PBS (pH 7.4) with $1 \%$

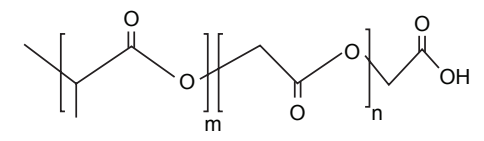

PLGA-COOH

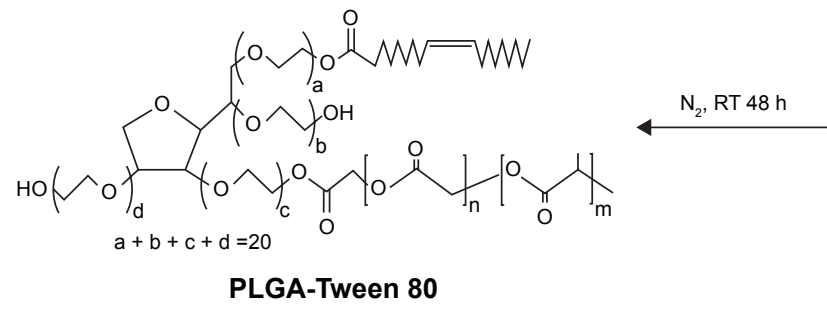

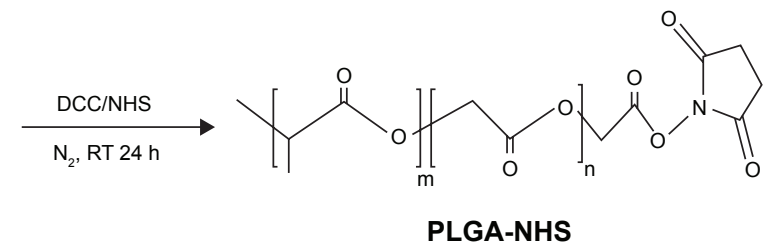

PLGA-NHS

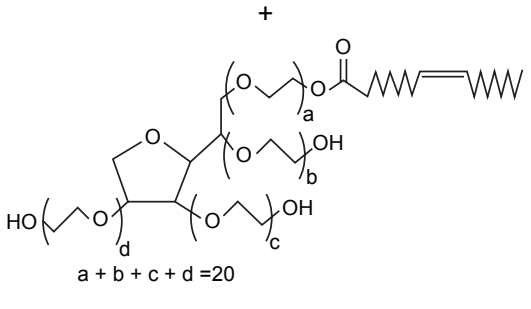

Tween 80

Figure I Synthetic representation of PLGA-Tween 80 copolymer.

Abbreviations: PLGA, poly(D,L-lactide-co-glycolide); DCC, N,N'-dicyclohexylcarbodiimide; NHS, N-hydroxysuccinimide; RT, room temperature; h, hours. 
Tween 80 at $37^{\circ} \mathrm{C}$ with stirring at $120 \mathrm{rpm}$. At time intervals ( 1 hour, 2 hours, 4 hours, 8 hours, 12 hours, 24 hours, 72 hours, 120 hours, and 168 hours), $10 \mathrm{~mL}$ of the medium was withdrawn for analysis of PTX concentration. Thereafter, the medium was replaced with an equal volume of fresh PBS. The concentration of PTX released was analyzed by high-performance liquid chromatography as described previously.

\section{Cellular uptake experiment}

A549 cells or A549/T cells were seeded at a density of $1 \times 10^{4}$ cells well ${ }^{-1}$ in a 24 -well plate, which kept cover slips in per well and allowed to attach overnight. Then, the cells were incubated with fresh medium containing $0.125 \mathrm{mg} \mathrm{mL}^{-1}$ C-6-loaded PLGA or PLGA-Tween 80 NPs for different incubation times with 1 hour, 2 hours, and 4 hours at $37^{\circ} \mathrm{C}$. C-6 was selected as a model compound based on its high sensitivity of determination in the cell cytoplasm. ${ }^{29}$ The sample wells were washed twice with PBS to remove the excess NPs that were not taken up by the cells. After fixing with $100 \mu \mathrm{L}$ $4 \%$ paraformaldehyde for 15 minutes, the cells were washed twice again with cold PBS. The intracellular fluorescence was determined using a fluorescence microscope (IX71; Olympus Corporation, Tokyo, Japan). The same imaging parameters were executed. The intensity of fluorescence was determined using a flow cytometer (BD Biosciences, San Jose, CA, USA). Both the qualitative images by fluorescence microscope and the quantitative mean fluorescence intensity analyzed by flow cytometry were done in triplicate.

\section{In vitro cytotoxicity}

The in vitro cytotoxicity of the drug-loaded PLGA-Tween 80 NPs was assessed using MTT assay. In brief, A549 cells and A549/T cells were seeded at a density of $5 \times 10^{3}$ cells/ well into a 96-well culture plate and incubated for 24 hours under the condition of $5 \% \mathrm{CO}_{2}$ at $37^{\circ} \mathrm{C}$. The medium was then replaced with fresh culture media containing Taxol ${ }^{\circledR}$, PTX-loaded PLGA NPs, and PTX-loaded PLGA-Tween 80 NPs at $1 \times 10^{-7} \mathrm{mg} \mathrm{mL}^{-1}, 1 \times 10^{-5} \mathrm{mg} \mathrm{mL}^{-1}, 1 \times 10^{-3} \mathrm{mg} \mathrm{mL}^{-1}$, and $1 \times 10^{-1} \mathrm{mg} \mathrm{mL}^{-1}$ equivalent PTX concentration. The control group was cells without treatment. After 48 hours, the medium was removed, and the wells were washed twice with PBS. The cells were then incubated with $100 \mu \mathrm{L}$ of medium and $10 \mu \mathrm{L}$ of $\operatorname{MTT}\left(5 \mathrm{mg} \mathrm{mL}^{-1}\right.$ in PBS) for 4 hours at $37^{\circ} \mathrm{C}$, and the precipitant was dissolved in $150 \mu \mathrm{L}$ of dimethyl sulfoxide using an automated shaker. The absorbance of each well was read at $570 \mathrm{~nm}$ by a microplate reader (Multiskan2 MK3; Thermo Fisher Scientific, Waltham, MA, USA).
Relative cell viability was calculated as the percentage in relation to untreated control cells. $\mathrm{IC}_{50}$ (concentration resulting in 50\% inhibition of cell growth) value for drugs was determined by SPSS software (Version 19.0). The experiment was repeated in triplicate.

\section{Cell apoptosis analysis}

The cell apoptosis assay was assessed using Annexin V-FITC/ PI double staining assay kit supplied by KeyGEN Biotech Co. Ltd. In brief, A549 cells and A549/T cells were seeded on the 24-well plates and treated with Taxol $^{\circledR}$, PTX-loaded PLGA NPs, and PTX-loaded PLGA-Tween 80 NPs at an equivalent PTX concentration of $1 \mu \mathrm{g} \mathrm{mL} \mathrm{m}^{-1}$ for 48 hours. The control group was cells without treatment. Then, the cells were collected in $400 \mu \mathrm{L}$ of binding buffer and mixed with $5 \mu \mathrm{L}$ of Annexin V-FITC and $10 \mu \mathrm{L}$ of PI for 15 minutes in the dark. The stained cells were analyzed using a flow cytometer (BD Biosciences).

\section{Cell cycle analysis}

A549 cells and A549/T cells were seeded on the 24-well plates with $3 \mathrm{~mL}$ culture medium containing Taxol ${ }^{\circledR}$, PTXloaded PLGA NPs, and PTX-loaded PLGA-Tween 80 NPs at an equivalent PTX concentration of $1 \mu \mathrm{g} \mathrm{mL}^{-1}$. The control group was cells without treatment. After 48 hours, adherent and nonadherent cells were collected and fixed with $70 \%$ cold ethanol at $4{ }^{\circ} \mathrm{C}$ for overnight. Then, RNase A $\left(0.1 \mathrm{mg} \mathrm{mL}^{-1}\right)$ was used to remove the interferential RNA. PI (1 $\mathrm{mg} \mathrm{mL}^{-1}$ ) was used to dye the nucleus for 30 minutes in the dark. The DNA content was measured by flow cytometry (BD Biosciences), and the percentage of cells in each phase of the cell cycle was evaluated using the ModFit software.

\section{In vivo antitumor efficacy}

A total of $5 \times 10^{6}$ A549 cells were resuspended in $100 \mu \mathrm{L}$ of PBS and injected subcutaneously into the right armpit of male nude mice $(n=40)$. The length and width of tumor were measured using a caliper, and the tumor volume was calculated by the formula, (length $\times$ width $\left.{ }^{2}\right) / 2 .{ }^{30}$ When tumors reached $100-150 \mathrm{~mm}^{3}$ in volume, mice were randomly assigned to four groups $(n=10)$ and injected through the tail vein with saline, Taxol, PTX-loaded PLGA NPs, and PTX-loaded PLGA-Tween 80 NPs at an equivalent PTX concentration of $10 \mathrm{mg} \mathrm{mL}^{-1}$, respectively. Tumor progression in the mice was measured every 2 days, and then animals were sacrificed at the end of the experiment. Tumors were removed and observed by H\&E staining. 


\section{Statistical analysis}

All experiments were repeated at least three times. For the NP fabrication, in vitro drug release, cellular uptake, and cell cycle/apoptosis analysis, each sample was repeated for three times. As for in vitro cytotoxicity assay and in vivo antitumor efficacy, six wells/each sample and ten mice per group were executed here. The mean \pm standard deviation was determined for each data in tables and figures. Statistical analysis was performed using a Student's $t$-test. The differences were considered statistically significant with $* P<0.05$.

\section{Results and discussion Characterization of synthesized copolymer}

PLGA, a polymer well established for enhancing drug solubility and bioavailability, has been widely used in the biomedical field of sustained and controlled release preparation and targeted drug delivery system. ${ }^{31}$ Various studies have also demonstrated that Tween 80-based NPs could inhibit the exocytosis of $\mathrm{p}$-gp, increasing the concentration of chemotherapeutics in tumor cells. ${ }^{32}$ In this study, PLGA-Tween 80 conjugate was first synthesized via a one-step esterification reaction. The chemical structure of PLGA-Tween 80 was confirmed by ${ }^{1} \mathrm{H}-\mathrm{NMR}$ and FTIR spectra. Figure $2 \mathrm{~A}$ shows the ${ }^{1} \mathrm{H}-\mathrm{NMR}$ spectra of PLGA and PLGA-Tween 80 copolymer. Compared to Tween 80 , the newly appearing signals at $3.5 \mathrm{ppm}$ in PLGA-Tween 80 were assigned to the $\mathrm{CH}_{2} \mathrm{CH}_{2} \mathrm{O}$ part of polyoxyethylene group of Tween 80 , which verified the successful esterification of Tween 80 . The molecular weight of PLGA-Tween 80 copolymers calculated by ${ }^{1} \mathrm{H}-\mathrm{NMR}$ results was $35,800 \mathrm{kDa}$ (Figure 2A). Figure 2B shows the FTIR spectra of PLGA and PLGATween 80 copolymers. Compared with PLGA, absorption band at $\sim 3,500 \mathrm{~cm}^{-1}$ was absent in PLGA-Tween 80 , which could be attributed to the $-\mathrm{COOH}$ of PLGA- $\mathrm{COOH}$, which thus proved the occurrence of successful esterification. All these results indicate that the intended copolymer has been synthesized.

\section{Characteristics of NP}

As reported, the hydrophobic segment of PTX can interact with PLGA upon encapsulation in NPs, thus resulting in high encapsulation efficiency and loading content. ${ }^{33}$ In addition, hydrophilic materials (Tween 80), on the surface of PLGA NPs, could prolong the circulation half-time in plasma. ${ }^{34} \mathrm{We}$ adopted a nanoprecipitation method to prepare PTX-loaded NPs. TPGS was used as a surfactant to facilitate NP formation in an acetone-water system. ${ }^{35}$ Tween 80 was not appropriate in fabricating PLGA NPs in the similar process as no stable and dispersed NPs can be recovered. Since applying Tween 80 as a surfactant cannot get a stable PLGA NP by the similar nanoprecipitation method in this research, we have not made comparison on following in vitro and in vivo experiment between PTX-loaded PLGA-Tween 80 and PTX-loaded PLGA NP formulated with Tween 80 . The size, size distribution, and surface charge of NPs are shown in Table 1. It could be seen that the average size of PLGA-Tween 80 NPs was much smaller, and the particle size distribution was much narrower than those of PLGA NPs. Tween 80 in the copolymer offers a steric stabilization effect, avoiding aggregation of the particles, indicating that Tween 80 could act as a coemulsifier in the fabrication process, resulting in a smaller particle size and a narrow size distribution. Besides, the surface charge of PLGA-Tween 80 NPs was higher than that of PLGA NPs in terms of absolute value, suggesting the presence of a Tween 80 layer on the surface of the NP. As shown in Figure 3A, transmission electron microscopy was used to examine the morphology of PTX-loaded NPs. The transmission electron microscope images revealed that PLGA-Tween 80 NPs were nanometer-sized spherical particles. Furthermore, the particle size observed from transmission electron microscope image was a little smaller than the size measured by particles size analyzer which detected the hydrodynamic diameter.

It is known that sustained controlled drug release is essential for effective treatment. ${ }^{36}$ Figure $3 \mathrm{~B}$ shows the in vitro release profiles of the PTX-loaded NPs. The results showed that $\sim 70 \%$ of PTX was released from the NPs within the first 24 hours, followed by a slow continuous release over the next 6 days. The sustained release of PTX from the NPs at pH 7.4 demonstrates that the PTX-loaded NPs are stable during circulation in the blood. Furthermore, due to the slowly release rate of PTX, the side effects of the drug could be reduced, and the therapeutic efficacy could be greatly enhanced.

\section{Cellular uptake experiment}

It is well known that the therapeutic effects depend on the internalization of the drug by cells. ${ }^{37}$ The cellular uptake of PLGA and PLGA-Tween 80 NPs was performed using C-6loaded NPs on A549 cells and A549/T cells. C-6, a fluorescence marker, has been reported as a probe for marking NPs in cellular uptake experiments. ${ }^{38}$ As shown in Figure 4A and $\mathrm{B}$, for both formulations, the cellular uptake of the NPs by A549 cells and A549/T cells was time dependent. The cellular uptake efficiency of PLGA-Tween $80 \mathrm{NPs}$ was seen to be higher than that of PLGA NPs on A549 cells, which suggested that PLGA-Tween 80 could effectively facilitate PTX 

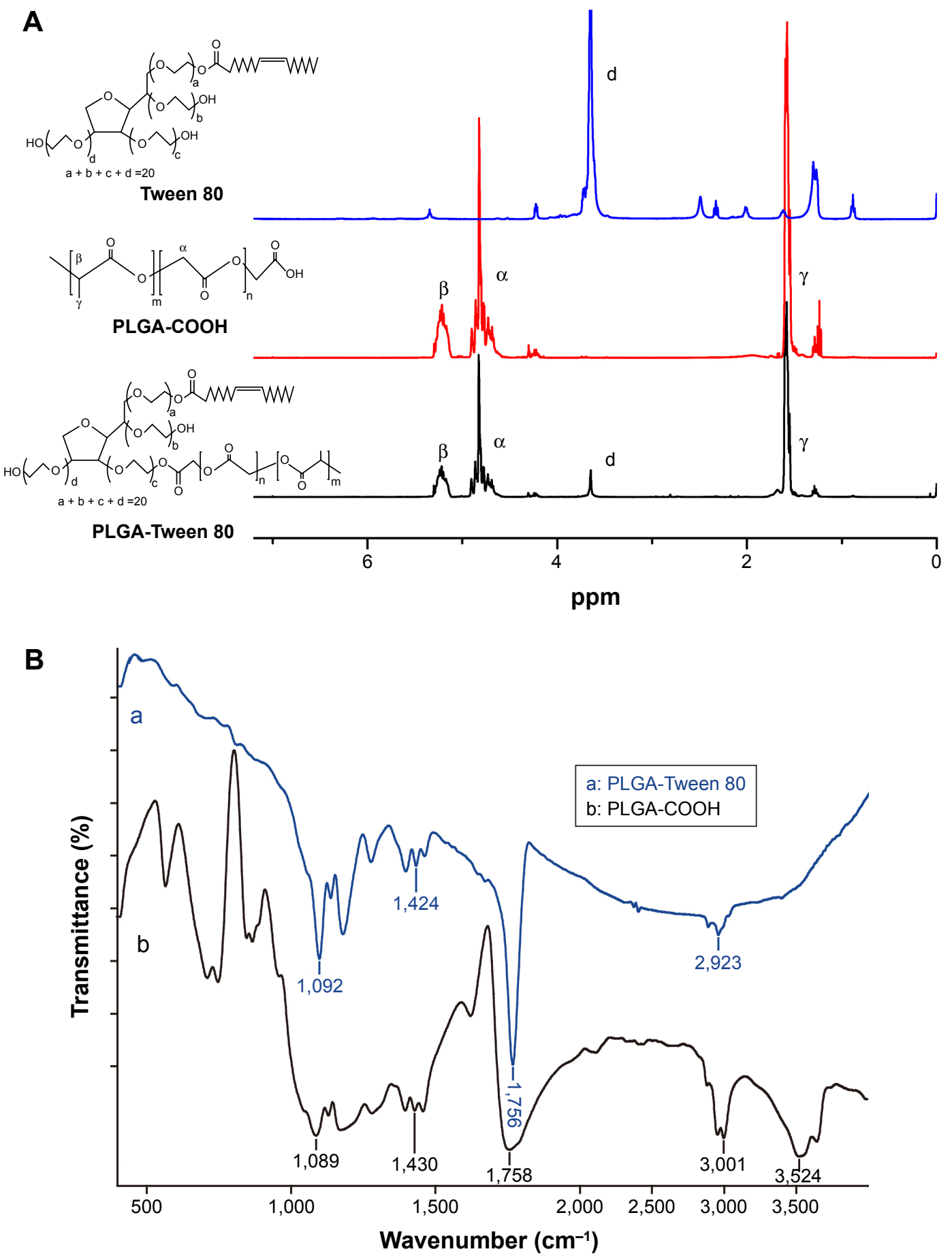

Figure 2 The chemical structure of PLGA and PLGA-Tween 80 copolymers.

Notes: 'H-NMR of PLGA and PLGA-Tween 80 copolymers (A). Fourier transform infrared (FT-IR) spectra of (a) PLGA and (b) PLGA-Tween 80 (B).

Abbreviation: PLGA, poly(D,L-lactide-co-glycolide).

Table I Particle size and zeta potential of PTX-loaded NP

\begin{tabular}{lllll}
\hline Polymer & $\begin{array}{l}\text { Drug } \\
\text { loading (\%) }\end{array}$ & $\begin{array}{l}\text { Particle } \\
\text { size }(\mathbf{n m})\end{array}$ & PDI & $\begin{array}{l}\text { Zeta potential } \\
(\mathbf{m v})\end{array}$ \\
\hline PLGA & 5 & $166.9 \pm 5.0$ & 0.24 & $-23.0 \pm 0.6$ \\
PLGA-Tween 80 & 5 & $156.5 \pm 8.6$ & 0.14 & $-15.4 \pm 1.1$ \\
\hline
\end{tabular}

Abbreviations: PTX, paclitaxel; PLGA, poly(D,L-lactide-co-glycolide); PDI, polydispersity index; NP, nanoparticle. into cells. But on A549/T cells, the difference between the cellular uptake of C-6-loaded PLGA and that of C-6-loaded PLGA-Tween 80 was larger as exhibited by remarkable brightness in Figure 4A and enhanced mean fluorescence in Figure 4B. It demonstrated that PLGA-Tween 80 could effectively facilitate drug into A549/T cells. 

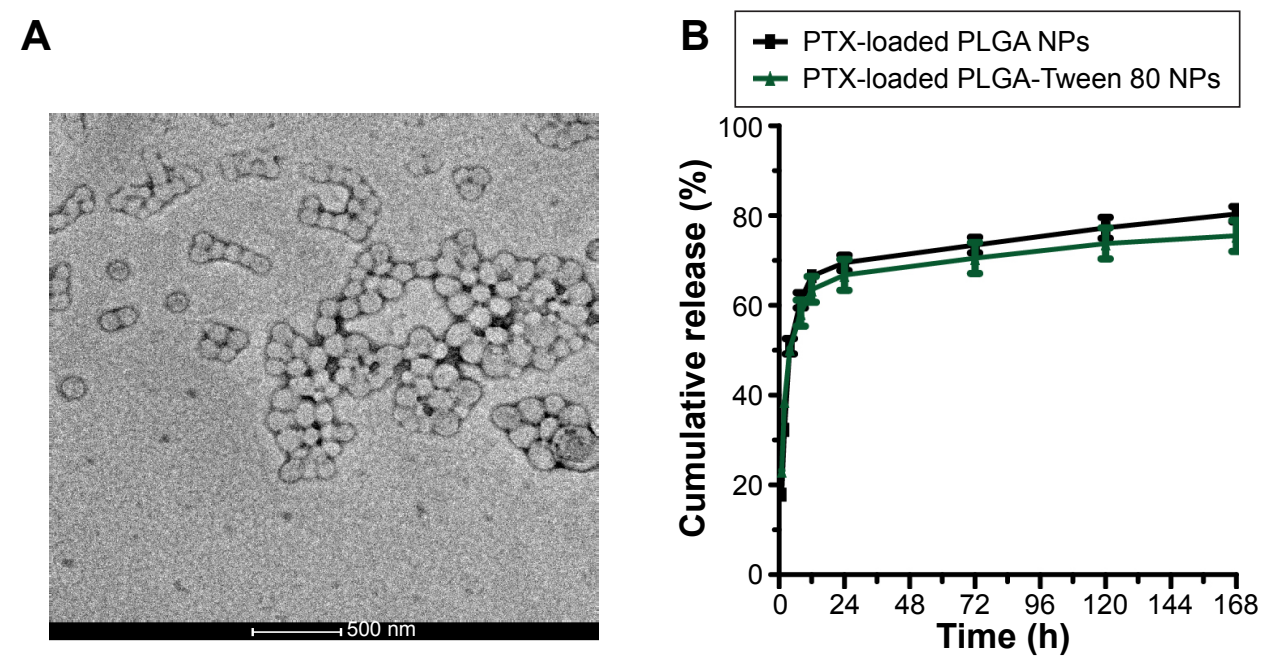

Figure 3 Characteristics of nanoparticles.

Notes: Transmission electron microscope image of PLGA-Tween 80 NPs (A). In vitro drug release behaviors of PTX-loaded NPs (B).

Abbreviations: PLGA, poly(D,L-lactide-co-glycolide); NPs, nanoparticles; PTX, paclitaxel; h, hours.

A
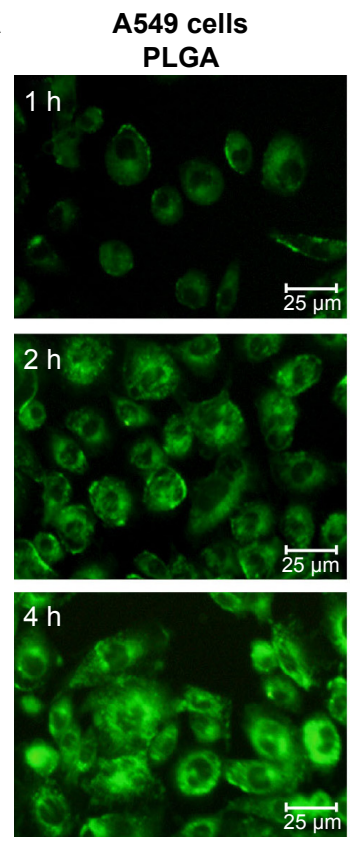

B

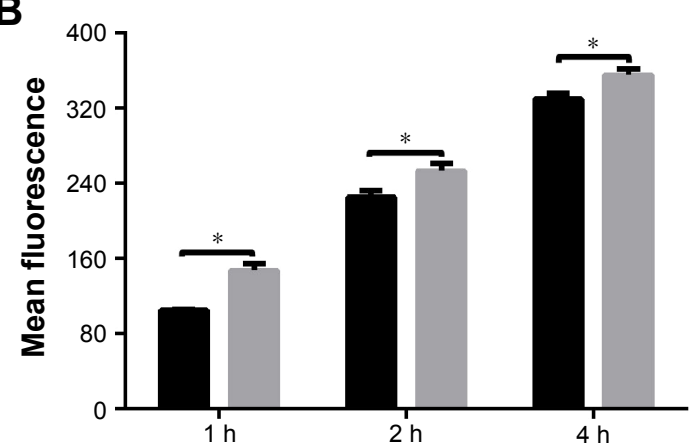

PLGA-Tween 80
A549/T cells
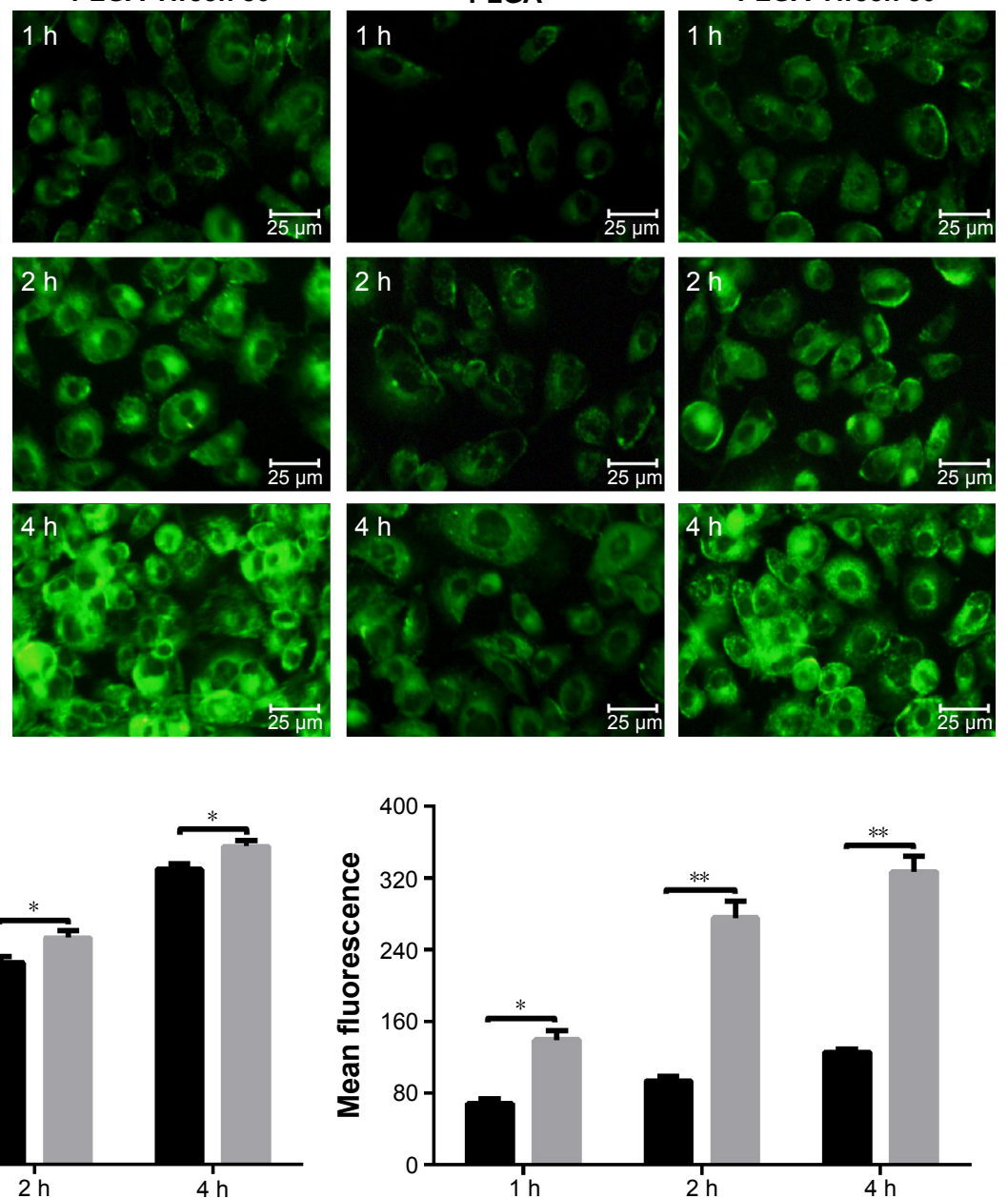

Figure 4 Cellular uptake of A549 and A549/T cell.

Notes: Fluorescence microscope images (A) and mean fluorescence intensity measured by flow cytometry (B) of C-6-loaded PLGA NPs and C-6-loaded PLGA-Tween 80 NPs in A549 cells (left) and A549/T (right) at different time points. Data were given as mean \pm SD ( $n=3)$. * and ** stand for statistical significance using Student's $t$-test with $P<0.05$ and $P<0.01$, respectively.

Abbreviations: PLGA, poly(D,L-lactide-co-glycolide); NPs, nanoparticles; h, hours; SD, standard deviation. 


\section{In vitro cytotoxicity experiment}

The cytotoxicity of Taxol ${ }^{\circledR}$ and PTX-loaded NPs against A549 and A549/T cells at the equivalent PTX concentrations of $1 \times 10^{-7} \mathrm{mg} \mathrm{mL}^{-1}, 1 \times 10^{-5} \mathrm{mg} \mathrm{mL}^{-1}, 1 \times 10^{-3} \mathrm{mg} \mathrm{mL}^{-1}$, and $1 \times 10^{-1} \mathrm{mg} \mathrm{mL}^{-1}(\mathrm{n}=4)$ were evaluated. It was shown in Figure 5 that the $\mathrm{IC}_{50}$ values of free PTX against A549 and A549/T cells were $0.002 \mathrm{mg} \mathrm{mL}^{-1}$ and $0.008 \mathrm{mg} \mathrm{mL}^{-1}$, respectively, which suggested that A549/T cells exhibited high drug resistance to PTX. In addition, the $\mathrm{IC}_{50}$ value of PTX-loaded PLGA-Tween $80 \mathrm{NPs}$ was $0.57 \mu \mathrm{g} \mathrm{mL}^{-1}$ against A549 cells and showed similar cytotoxicity with free PTX and PTX-loaded PLGA NPs, which suggested that PLGATween 80 copolymer had little effect on the sensitive cells. However, the $\mathrm{IC}_{50}$ of PLGA-Tween 80 NPs against A549/T cells was $1.26 \mu \mathrm{g} \mathrm{mL}^{-1}$, which was eightfold and threefold lower than that of free PTX and that of PLGA NPs, suggesting that in A549/T cells, PLGA-Tween 80 NPs displayed more remarkable cytotoxicity than free PTX and PLGA NPs. Since that the cellular uptake of PLGA-Tween 80 NPs in A549/T cells was significantly higher than that of PLGA NPs (Figure 4), the increased uptake of PTX in PLGA-Tween 80 caused more cytotoxicity (Figure 5 ). These could explain why PLGA-Tween 80 showed obvious effects to A549/T cells but showed similar cytotoxicity compared with free PTX on A549 cells. Thus, PLGA-Tween 80 copolymer could increase the anticancer activity of PTX and overcome PTX resistance in lung cancer.

\section{Cell cycle analysis}

It has been proved that the antitumor mechanisms of PTX were associated with apoptosis, mitosis inhibition, and cell cycle arrest in $\mathrm{G} 2 / \mathrm{M}$ phase. ${ }^{39}$ Thus, the increased $\mathrm{G} 2 / \mathrm{M}$ phase arrest indicated more therapeutic effect of PTX. The cell cycle arrest of Taxol $^{\circledR}$ and PTX-loaded NPs against A549 and A549/T cells at the equivalent PTX concentrations of $1 \mu \mathrm{g} \mathrm{mL}{ }^{-1}$ was examined. As shown in Figure 6, A549/T cells treated with Taxol ${ }^{\circledR}$ had similar cell cycle distribution (G2/M, 11.1\%) compared with control group (G2/M, 4.9\%), demonstrating that A549/T cells exhibited high drug resistance to PTX. On the other hand, PTX-loaded PLGA-Tween 80 NPs had relatively larger cell cycle arrest in A549 cells and A549/T cells than PLGA NPs and Taxol ${ }^{\circledR}(P<0.05)$, which suggested that PLGA-Tween 80 could significantly block the cells in the G2/M phase. As shown in Figure 6, cell cycle arrest in $\mathrm{G} 2 / \mathrm{M}$ phase was significantly increased from $14.8 \pm 4.8$ and was $51.1 \% \pm 10.0 \%$ significant for PTX-loaded PLA-Tween 80 NPs on A549 cells, which was 2.1 - and 1.4fold of Taxol ${ }^{\circledR}$ and PTX-loaded PLGA NPs. On A549/T cells, PTX-loaded PLGA-Tween 80 NPs enhanced the cell cycle arrest on $\mathrm{G} 2 / \mathrm{M}$ phase up to $32.5 \% \pm 8.0 \%$, which was $\sim 5$-, 3.0-, and 1.4-fold higher than the control, $\mathrm{Taxol}^{\circledR}$, and PTXloaded PLGA NPs, respectively (Figure 6J). These results indicated that PLGA-Tween 80 could induce cell cycle arrest in PTX-resistant A549/T cells.

\section{Cell apoptosis assay}

To certify that PLGA-Tween 80 NPs could induce multidrug resistant cell apoptosis, Annexin-PI staining assay was performed to analyze the percentage of early cell apoptosis treated with various formulation of PTX. Figure 7 shows that PTX administration for 48 hours displayed limited apoptosis compared with control group in A549/T cells, which demonstrated the strong resistance of A549/T to PTX. On the other hand, PTX-loaded PLGA-Tween 80 NPs caused
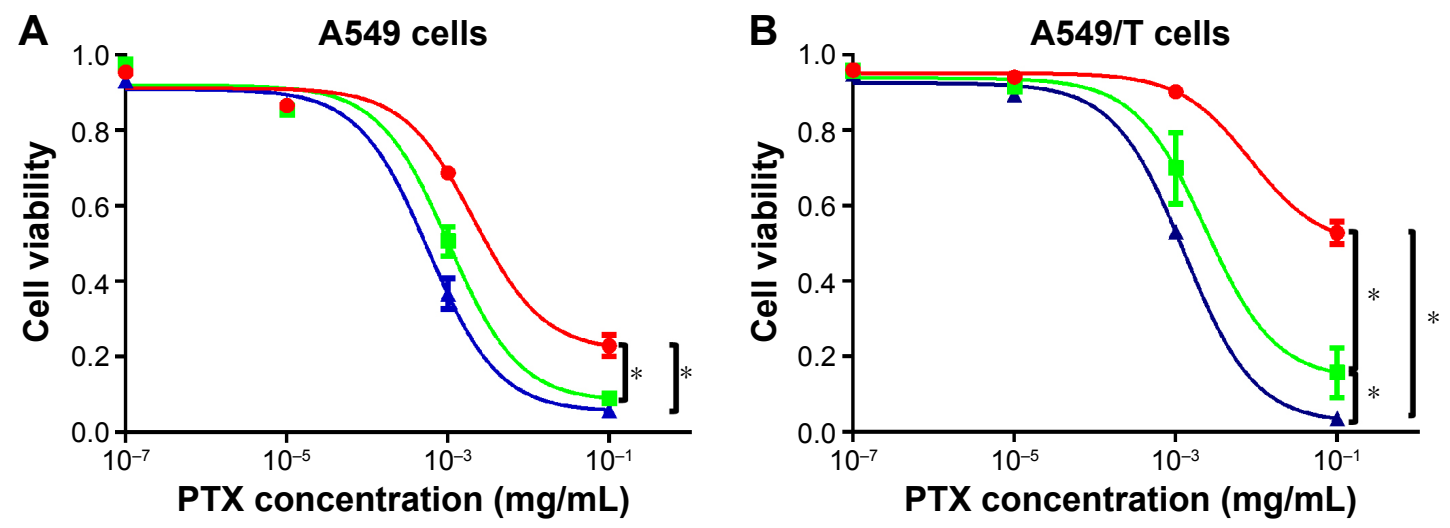

$$
\multimap \text { Taxol } \quad \text { PLGA(PTX) } \quad \text { PLGA-Tween 80(PTX) }
$$

Figure 5 PLGA-Tween 80 nanoparticle effectively inhibited the growth of both A549 and A549/T cell line.

Notes: In vitro cytotoxicity against A549 (A) and A549/T (B) cancer cells after treatment with Taxol, PTX-loaded PLGA NPs (simply PLGA[PTX]), PTX-loaded PLGATween 80 NPs (simply PLGA-Tween 80[PTX]), respectively, for 48 h. *Stands for statistical significance using Student's $t$-test with $P<0.05$.

Abbreviations: PLGA, poly(D,L-lactide-co-glycolide); PTX, paclitaxel; NPs, nanoparticles; h, hours. 

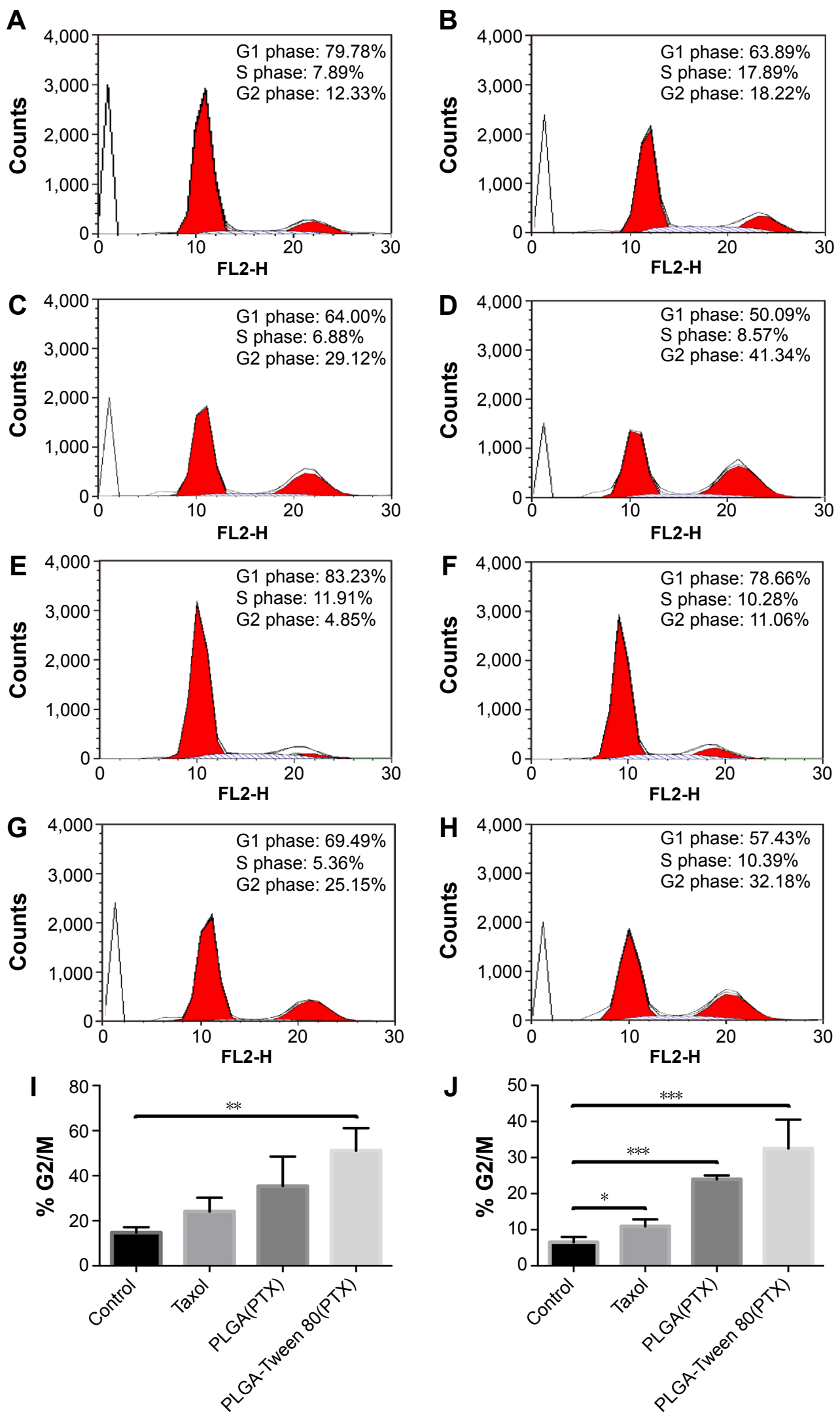

Figure 6 PLGA-Tween 80 nanoparticles evidently induced cell cycle arrest in both A549 and A549/T cell line.

Notes: Cell cycle analysis of A549 cells by flow cytometry treated with blank medium (A), Taxol (B), PTX-loaded PLGA NPs (C), and PTX-loaded PLGA-Tween 80 NPs (D) for $24 \mathrm{~h}$. Cell cycle analysis of A549/T cells by flow cytometry treated with blank medium (E), Taxol (F), PTX-loaded PLGA NPs (G), and PTX-loaded PLGA-Tween 80 NPs (H) for 24 h. G2/M percentage of A549 cells (I) and A549/T cells (J) after treated with Taxol, PTX-loaded PLGA NPs, and PTX-loaded PLGA-Tween 80 NPs for 24 h, respectively. *, **, and *** stand for statistical significance using Student's $t$-test with $P<0.05, P<0.0 \mathrm{I}$, and $P<0.00 \mathrm{I}$, respectively. Abbreviations: PTX, paclitaxel; PLGA, poly(D,L-lactide-co-glycolide); NPs, nanoparticles; h, hours. 
A

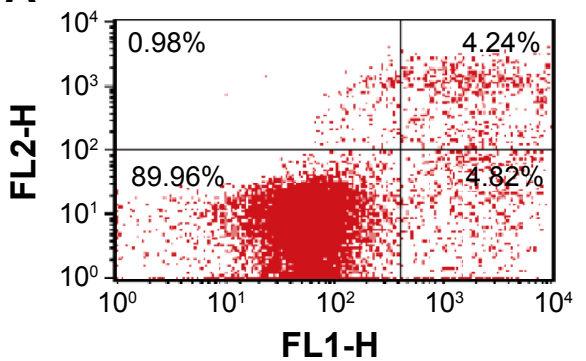

C

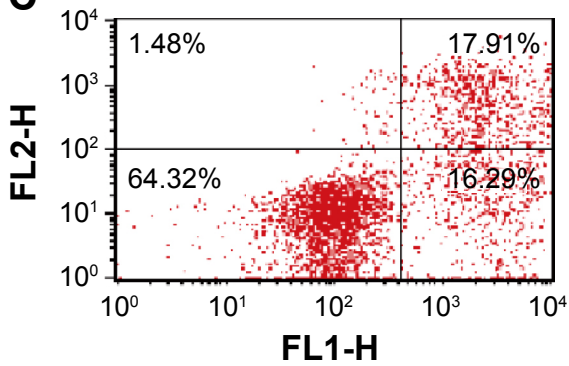

E

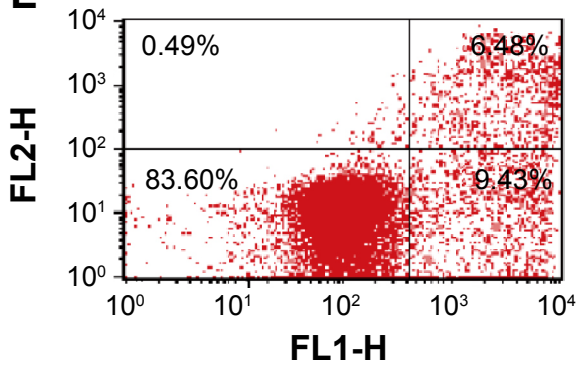

G
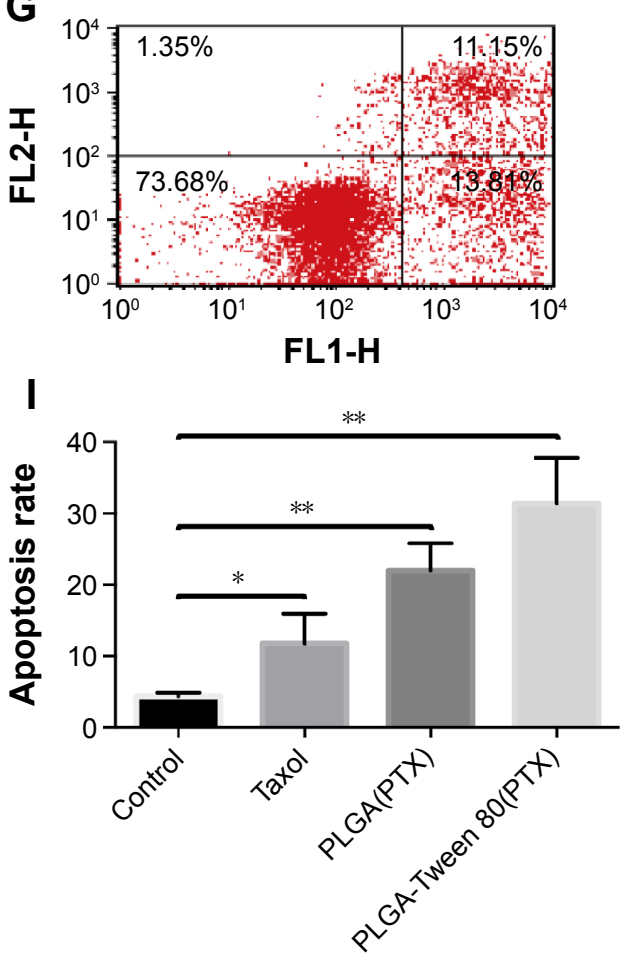

B

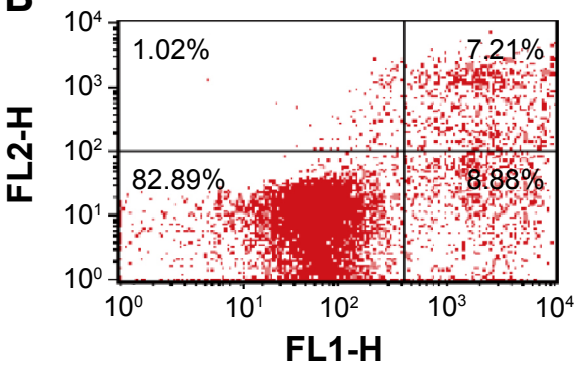

D

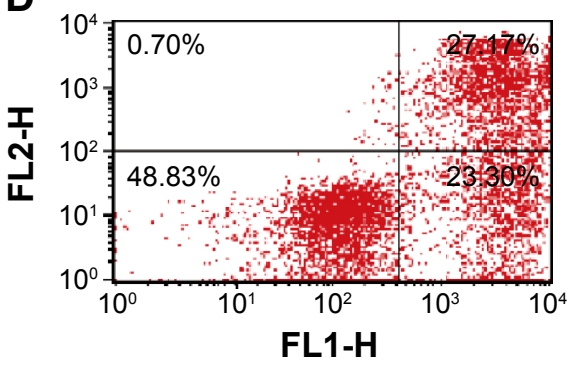

F

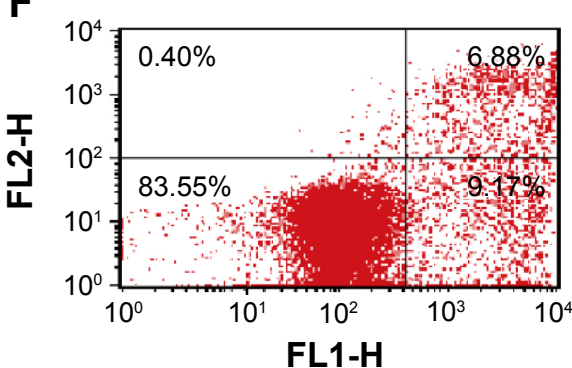

H

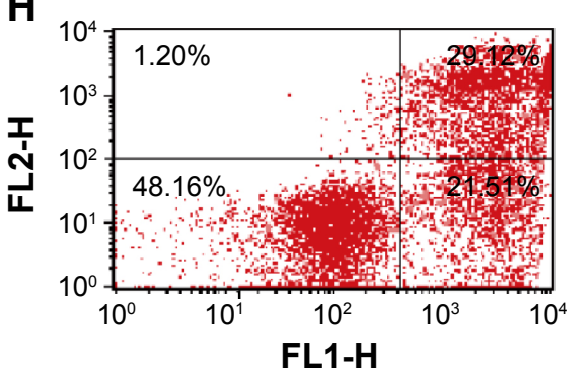

$\mathbf{J}$

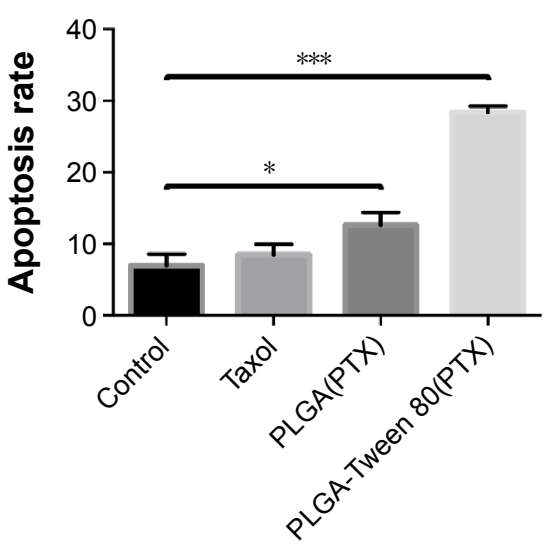

Figure 7 PLGA-Tween 80 nanoparticles evidently induced cell apoptosis in both A549 and A549/T cell line.

Notes: Cell apoptosis analysis of A549 cells by flow cytometry using staining of Annexin V-FITC and PI treated with blank medium (A), Taxol (B), PTX-loaded PLGA NPs (C), and PTX-loaded PLGA-Tween 80 NPs (D) for 24 h. Cell apoptosis analysis of A549/T cells by flow cytometry using staining of Annexin V-FITC and PI treated with blank medium (E), Taxol (F), PTX-loaded PLGA NPs (G), and PTX-loaded PLGA-Tween 80 NPs (H) for 24 h. The percentage of double FITC and PI positive population of A549 cells (I) and A549/T cells (J) after treatment with Taxol, PTX-loaded PLGA NPs, and PTX-loaded PLGA-Tween 80 NPs for 24 h, respectively. $* P<0.05 ; * * P<0.0$ I; $* * * P<0.001$. Abbreviations: PI, propidium iodide; PTX, paclitaxel; PLGA, poly(D,L-lactide-co-glycolide); NPs, nanoparticles; h, hours; V-FITC, fluorescein isothiocyanate. 
relatively higher apoptosis in A549 cells and A549/T cells than PLGA NPs and Taxol ${ }^{\circledR}$, which suggested PLGA-Tween 80 could induce apoptosis significantly. For example, the percentage of early apoptosis of Taxol ${ }^{\circledR}$ and PTX-loaded PLGA NPs in A549/T cells was 6.88\% and $11.15 \%$, respectively. However, the percentage of early cell apoptosis of PLGA-Tween 80 NPs was 29.12\%. As shown in Figure 7I, the apoptosis induced by Taxol, PTX-loaded PLGA NPs, and PLGA-Tween 80 NPs on A549 cells was $11.8 \% \pm 4.2 \%$, $22.0 \% \pm 3.8 \%$, and $31.4 \% \pm 6.4 \%$, respectively. On the contrary, PTX-loaded PLGA-Tween 80 NPs caused more apoptosis on A549/T cells compared with Taxol and PTXloaded PLGA NPs as shown in Figure $7 \mathrm{~J}(P<0.01)$. The ratio of apoptosis was increased from $6.9 \% \pm 1.7 \%, 8.5 \% \pm 1.5 \%$, and $12.6 \% \pm 1.8 \%$ for the control, Taxol, and PLGA NPs, respectively, up to $28.4 \% \pm 0.9 \%$ for PLGA-Tween $80 \mathrm{NPs}$. These results demonstrated that PLGA-Tween 80 copolymer significantly lowered the apoptosis threshold of drug resistant cells and enhanced PTX-induced apoptosis.

\section{In vivo antitumor efficacy}

The average tumor size and body weight were measured during the experiment to monitor the antitumor efficacy and the toxicity (Figure 8). As shown in Figure 8A, weak tumor inhibitory effect was caused by the Taxol group. PLGA-Tween 80 NPs treatment could inhibit the growth of the tumor with final tumor volume $=238.5 \mathrm{~mm}^{3}$. The final tumor volume of Taxol group and PLGA group was
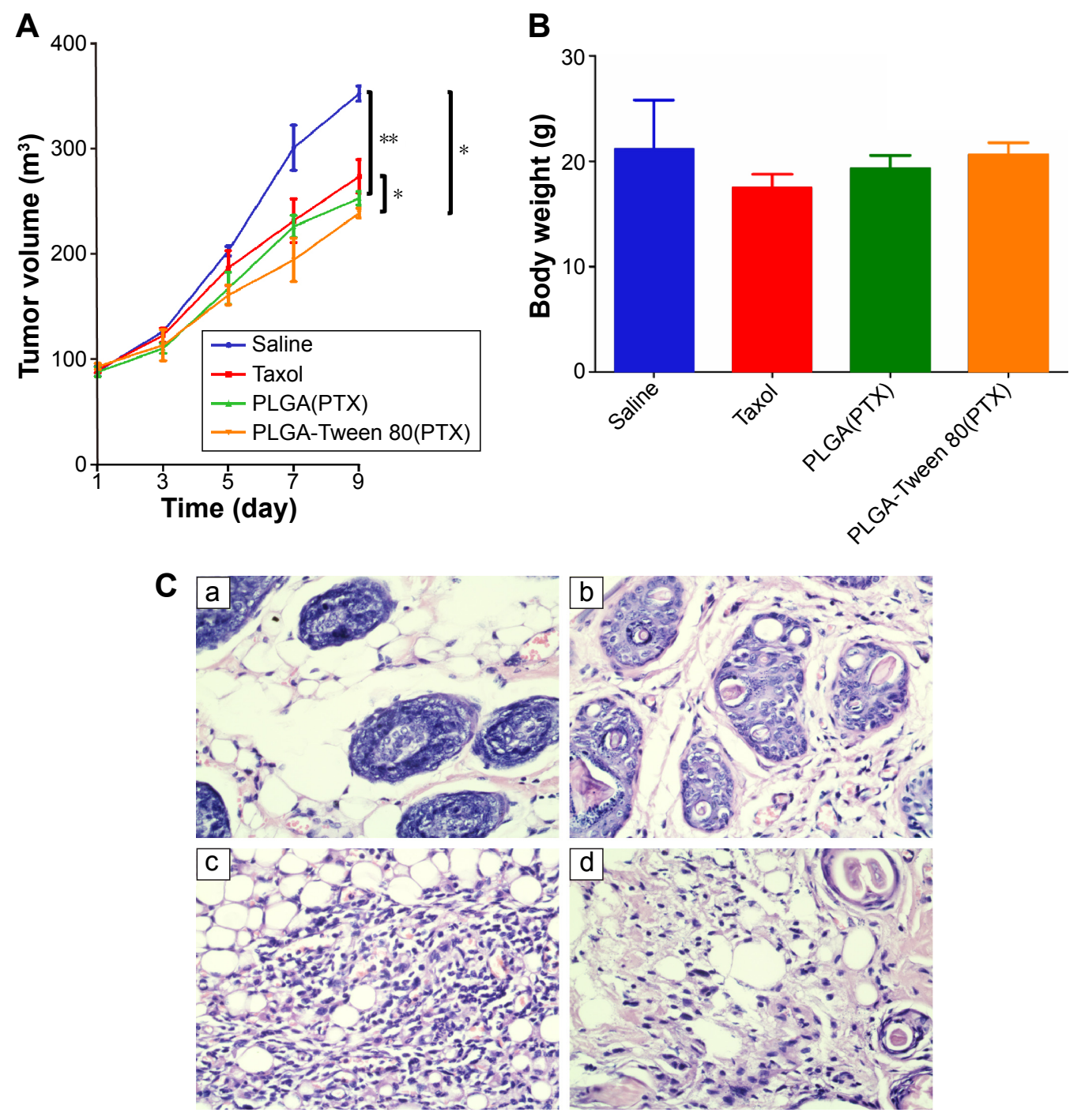

Figure 8 In vivo antitumor effects of the PTX loaded-NPs against saline and Taxol.

Notes: (A) Tumor growth curves of A549 tumor-bearing mice model that received the different treatments indicated. (B) Weights of tumor-bearing mice in different groups. (C) Images of H\&E-stained sections. Tumors were excised from subcutaneous tumor-bearing mice on I0th day after different treatment: saline (a), Taxol (b), PTX-loaded PLGA NPs (c), and PTX-loaded PLGA-Tween 80 NPs (d). Images were obtained under Olympus microscope using a 40× objective. The * stands for statistical significance using Student's $t$-test with $P<0.05$. $* P<0.05 ; * * P<0.0$ I.

Abbreviations: PTX, paclitaxel; NPs, nanoparticles; PLGA, poly(D,L-lactide-co-glycolide). 
$273.3 \mathrm{~mm}^{3}$ and $252.6 \mathrm{~mm}^{3}$, which indicated that PLGATween 80 could enhance PTX induced apoptosis. The tumor volume of PLGA-Tween 80 group was only $87 \%$ of the Taxol group, that is, the antitumor efficacy of PLGA-Tween 80 NPs was superior to that of PTX treatments, which suggested that PLGA-Tween 80 NPs had significant advantages over Taxol in suppressing A549 solid tumors. However, there is no significant difference between PLGA-Tween 80 NPs and PLGA NPs in antitumor efficacy $(P>0.05)$. Furthermore, the difference among Taxol, PLGA NPs, and PLGA-Tween 80 NPs was not so remarkable, although the difference between Taxol and PLGA-Tween 80 NPs showed significant difference $(P<0.05)$. Moreover, the body weights of mice (Figure $8 \mathrm{~B}$ ) with any treatments had no serious loss, which suggested that no significant toxicity was induced by Taxol or PLGA-Tween 80. Tumor tissue was investigated by HE staining (Figure 8C). It seems that the antitumor efficacy of PTX-loaded PLGA-Tween 80 NPs was the strongest as compared to other groups, which was consistent with the in vitro cell experiment. However, it seems that single drugloaded NPs demonstrated some kind of efficacy against tumor growth inhibition but not so efficient. ${ }^{21}$ It may be attributed to the tumor heterogeneity, complexity of drug resistance, and barriers of NPs circulating and crossing in vivo. ${ }^{19,29,30}$ There are already substantial efforts to incorporate multiple functionalities and moieties within the nanoparticle design. The design for site-specific delivery of therapeutics will be considered in future such as inducing the targeting agent. While there are great strides made in nanomedicine, the nanoparticles formulations for anticancer drug are still limited in clinical evaluation and practice. The considering about the barriers to translation are still absent, such as the blood compartment effect on the in vivo drug retention, tumor extravasation and accumulation, tumor penetration and tumor uptake. The obstacles such as the nonspecific distribution and inadequate drug accumulation remain challenges. The critical features also need further study on the characters of nanoparticles such as the size, zeta potential, shape, stability, surface roughness and functionalization, etc. In future, combinational chemotherapeutic drug treatment or combined with immunotherapy would be recommended to get complete tumor inhibition. ${ }^{40-43}$

\section{Conclusion}

PLGA-Tween 80 NPs delivering PTX to overcome PTX resistance in lung cancer cells were first designed and investigated. PLGA-Tween 80 could effectively deliver PTX, facilitate drug into A549 and A549/T cells, and exhibit detectable cytotoxicity on A549/T cells. The $\mathrm{IC}_{50}$ of PLGA-Tween 80 NPs against A549/T cells was eightfold lower than that of free PTX. Downregulation of $\mathrm{p}$-gp protein by PLGA-Tween 80 could increase PTX accumulation in A549/T cells. Better antitumor efficacy of PLGA-Tween 80 NPs was also observed on nude mice bearing A549 cells. Therefore, the codelivery of PTX by PLGA-Tween 80 could be a more powerful approach for effective chemotherapy in resistant human lung cancer.

\section{Acknowledgment}

This work was supported by NSFC no 81301929 and National Key Scientific Instrument Special Program of China no 2013 YQ030923 and Hubei Province Health and Family Planning Scientific Research Project no WJ2015Q009.

\section{Disclosure}

The authors report no conflicts of interest in this work.

\section{References}

1. Siegel R, Ma J, Zou Z, Jemal A. Cancer statistics, 2014. CA Cancer J Clin. 2014;64(1):9-29.

2. Parkin DM, Bray F, Ferlay J, Pisani P. Global cancer statistics, 2002. CA Cancer J Clin. 2005;55(2):74-108.

3. Weiss RB, Donehower RC, Wiernik PH, et al. Hypersensitivity reactions from taxol. J Clin Oncol. 1990;8(7):1263-1268.

4. Sosnik A. Reversal of multidrug resistance by the inhibition of ATPbinding cassette pumps employing "generally recognized as safe" (GRAS) nanopharmaceuticals: a review. Adv Drug Deliv Rev. 2013; 65(13-14):1828-1851.

5. Zhu X, Li Y, Xie C, et al. miR-145 sensitizes ovarian cancer cells to paclitaxel by targeting Sp1 and Cdk6. Int J Cancer. 2014;135(6): $1286-1296$.

6. Silva R, Vilas-Boas V, Carmo H, et al. Modulation of P-glycoprotein efflux pump: induction and activation as a therapeutic strategy. Pharmacol Ther. 2015;149:1-123.

7. Saxena V, Hussain MD. Polymeric mixed micelles for delivery of curcumin to multidrug resistant ovarian cancer. J Biomed Nanotechnol. 2013;9(7):1146-1154.

8. Singh MS, Lamprecht A. Cargoing P-gp inhibitors via nanoparticle sensitizes tumor cells against doxorubicin. Int J Pharm. 2015;478(2): 745-752.

9. Patel K, Patil A, Mehta M, Gota V, Vavia P. Medium chain triglyceride (MCT) rich, paclitaxel loaded self nanoemulsifying preconcentrate (PSNP): a safe and efficacious alternative to taxol. J Biomed Nanotechnol. 2013;9(12):1996-2006.

10. Shi Y, van der Meel R, Theek B, et al. Complete regression of xenograft tumors upon targeted delivery of paclitaxel via Pi-Pi stacking stabilized polymeric micelles. ACS Nano. 2015;9(4):3740-3752.

11. Fu H, Shi K, Hu G, et al. Tumor-targeted paclitaxel delivery and enhanced penetration using TAT-decorated liposomes comprising redox-responsive poly(ethylene glycol). J Pharm Sci. 2015;104(3): 1160-1173.

12. Baek J, Cho C. Controlled release and reversal of multidrug resistance by co-encapsulation of paclitaxel and verapamil in solid lipid nanoparticles. Int J Pharm. 2014;478(2):617-624.

13. Shapira A, Livney YD, Broxterman HJ, Assaraf YG. Nanomedicine for targeted cancer therapy: towards the overcoming of drug resistance. Drug Resist Updat. 2011;14(3):150-163. 
14. Yan F, Zhang C, Zheng Y, et al. The effect of poloxamer 188 on nanoparticle morphology, size, cancer cell uptake, and cytotoxicity. Nanomedicine. 2010;6(1):170-178.

15. Tran TH, Nguyen CT, Gonzalez-Fajardo L, et al. Long circulating selfassembled nanoparticles from cholesterol-containing brush-like block copolymers for improved drug delivery to tumors. Biomacromolecules. 2014; 15(11):4363-4375.

16. Lancelot A, Sierra T, Serrano JL. Nanostructured liquid-crystalline particles for drug delivery. Expert Opin Drug Deliv. 2014;11(4): 547-564.

17. Draz MS, Fang BA, Zhang P, et al. Nanoparticle-mediated systemic delivery of siRNA for treatment of cancers and viral infections. Theranostics. 2014;4(9):872-892.

18. Yin RX, Yang DZ, Wu JZ. Nanoparticle drug- and gene-eluting stents for the prevention and treatment of coronary restenosis. Theranostics 2014;4(2):175-200.

19. Wu YP, Chu Q, Tan SW, et al. D- $\alpha$-tocopherol polyethylene glycol succinate-based derivative nanoparticles as a novel carrier for paclitaxel delivery. Int J Nanomed. 2015;10:5219-5235.

20. Srivatsan A, Chen X. Recent advances in nanoparticle-based nuclear imaging of cancers. Adv Cancer Res. 2014;124:83-129.

21. Choi KY, Silvestre OF, Huang X, et al. A nanoparticle formula for delivering siRNA or miRNAs to tumor cells in cell culture and in vivo. Nat Protoc. 2014;9(8):1900-1915.

22. Jeong B, Bae YH, Kim SW. Drug release from biodegradable injectable thermosensitive hydrogel of PEG-PLGA-PEG triblock copolymers. $J$ Control Release. 2000;63(1-2):155-163.

23. Zhang K, Tang X, Zhang J, et al. PEG-PLGA copolymers: their structure and structure-influenced drug delivery applications. J Control Release. 2014;183:77-86.

24. Menon JU, Jadeja P, Tambe P, Vu K, Yuan B, Nguyen KT. Nanomaterials for photo-based diagnostic and therapeutic applications. Theranostics. 2013;3(3):152-166.

25. Kirtane AR, Kalscheuer SM, Panyam J. Exploiting nanotechnology to overcome tumor drug resistance: challenges and opportunities. $A d v$ Drug Deliv Rev. 2013;65(13-14):1731-1747.

26. Wan CP, Letchford K, Leung D, Jackson JK, Burt HM. Mixed molecular weight copolymer nanoparticles for the treatment of drug-resistant tumors: formulation development and cytotoxicity. J Pharm Sci. 2014; 103(12):3966-3976.

27. Mudra DR, Borchardt RT. Absorption barriers in the rat intestinal mucosa. 3: effects of polyethoxylated solubilizing agents on drug permeation and metabolism. J Pharm Sci. 2010;99(2):1016-1027.

28. Li M, Si L, Pan H, et al. Excipients enhance intestinal absorption of ganciclovir by P-gp inhibition: assessed in vitro by everted gut sac and in situ by improved intestinal perfusion. Int J Pharm. 2011;403(1-2): $37-45$.

29. Shen J, Yin Q, Chen L, Zhang Z, Li Y. Co-delivery of paclitaxel and survivin shRNA by pluronic P85-PEI/TPGS complex nanoparticles to overcome drug resistance in lung cancer. Biomaterials. 2012;33(33): $8613-8624$.
30. Bao YL, Guo YY, Zhuang XT, et al. D- $\alpha$-tocopherol polyethylene glycol succinate-based redoxSensitive paclitaxel prodrug for overcoming multidrug resistance in cancer cells. Mol Pharm. 2014;11(9): 3196-3209.

31. Zhou P, An T, Zhao C, et al. Lactosylated PLGA nanoparticles containing $\varepsilon$-polylysine for the sustained release and liver-targeted delivery of the negatively charged proteins. Int J Pharm. 2015;478(2):633-643.

32. Moreno-Sanz G, Barrera B, Armirotti A, et al. Structural determinants of peripheral O-arylcarbamate FAAH inhibitors render them dual substrates for Abcb1 and Abcg2 and restrict their access to the brain. Pharmacol Res. 2014;87:87-93.

33. Feng SS. 15. Vitamin E TPGS based nanoparticles of biodegradable polymers for controlled release of anticancer drugs: original research article: a novel controlled release formulation for the anticancer drug paclitaxel (taxol): PLGA nanoparticles containing vitamin E TPGS (2003). J Control Release. 2014;190:58-60.

34. Zeng X, Tao W, Mei L, Huang L, Tan C, Feng SS. Cholic acidfunctionalized nanoparticles of star-shaped PLGA-vitamin E TPGS copolymer for docetaxel delivery to cervical cancer. Biomaterials. 2013; 34(25):6058-6067.

35. Sun Y, Yu B, Wang G, et al. Enhanced antitumor efficacy of vitamin E TPGS-emulsified PLGA nanoparticles for delivery of paclitaxel. Colloids Surf B Biointerfaces. 2014;123:716-723.

36. Kim SY, Hwang J, Seo J, Shin US. Production of CNT-taxol-embedded PCL microspheres using an ammonium-based room temperature ionic liquid: as a sustained drug delivery system. J Colloid Interface Sci. 2015;442:147-153.

37. Naeem M, Kim W, Cao J, Jung Y, Yoo JW. Enzyme/pH dual sensitive polymeric nanoparticles for targeted drug delivery to the inflamed colon Colloids Surf B Biointerfaces. 2014;123:271-278.

38. Zhang P,Hu L, Wang Y, Wang J, Feng L, Li Y.Poly(epsilon-caprolactone)block-poly(ethyl ethylene phosphate) micelles for brain-targeting drug delivery: in vitro and in vivo valuation. Pharm Res. 2010;27(12): 2657-2669.

39. Zhang W, Shi Y, Chen Y, et al. Enhanced antitumor efficacy by paclitaxel-loaded pluronic P123/F127 mixed micelles against non-small cell lung cancer based on passive tumor targeting and modulation of drug resistance. Eur J Pharm Biopharm. 2010;75(3):341-353.

40. Guo YY, Wang D, Song QL, et al. Erythrocyte membrane-enveloped polymeric nanoparticles as nano-vaccine for induction of antitumor immunity against melanoma. ACS Nano. 2015;9(7):6918-6933.

41. Blanco E, Shen H, Ferrari M. Principles of nanoparticle design for overcoming biological barriers to drug delivery. Nat Biotechnol. 2015 ; 33(9):941-951.

42. Yu Y, Tan S, Zhao S, et al. Antitumor activity of docetaxel-loaded polymeric nanoparticles fabricated by Shirasu porous glass membraneemulsification technique. Int J Nanomed. 2013;8:2641-2652.

43. Eetezadi S, Ekdawi SN, Allen C. The challenges facing block copolymer micelles for cancer therapy: In vivo barriers and clinical translation. Adv Drug Deliv Rev. 2015;91:7-22.
International Journal of Nanomedicine

\section{Publish your work in this journal}

The International Journal of Nanomedicine is an international, peerreviewed journal focusing on the application of nanotechnology in diagnostics, therapeutics, and drug delivery systems throughout the biomedical field. This journal is indexed on PubMed Central, MedLine, CAS, SciSearch $®$, Current Contents $\AA /$ Clinical Medicine,

\section{Dovepress}

Journal Citation Reports/Science Edition, EMBase, Scopus and the Elsevier Bibliographic databases. The manuscript management system is completely online and includes a very quick and fair peer-review system, which is all easy to use. Visit http://www.dovepress.com/ testimonials.php to read real quotes from published authors. 